\title{
Control of grid side converter in wind power based PMSG with PLL method
}

\author{
Rania Moutchou, Ahmed Abbou \\ Research team in Electrical Energy and Control (RTEEC), Mohammadia School of Engineers (EMI), Mohammed V \\ University in Rabat, Morocco
}

\section{Article Info \\ Article history: \\ Received Aug 23, 2021 \\ Revised Sep 28, 2021 \\ Accepted Oct 6, 2021}

\section{Keywords:}

Grid side converter

Machine side converter

Maximum power point tracking

Phase-locked loop

Permanent magnet synchronous generator

Pulse width modulation

Vector control

\begin{abstract}
Wind power is one of the most promising renewable energy sources. Due to a constantly increasing penetration rate in power grids in order to comply with interconnection requirements. This article targets the impact of a permanent magnet synchronous generator (PMSG) which is the subject of most attention due to low cost and maintenance requirements, driven by a wind turbine with the necessary power electronic converters that allow wind turbines to operate at variable speed, and connected to the grid for power generation more efficiently by the phase-locked loop (PLL) method in order to synchronize it. Thus, the proposed control technicals are based on vector control (VC) to achieve maximum power point tracking (MPPT), keep the DC link voltage constant, and control the speed and current at the generator side and grid side in PMSG which provides controllability of the reactive power supplied to the network. Therefore, the response of the PLL is analyzed and the simulation results of the dynamic model of the system is developed in Matlab / Simulink. The study results exhibit the excellent performance with high robustness, by improving the system efficiency to $98.72 \%$.
\end{abstract}

This is an open access article under the CC BY-SA license.

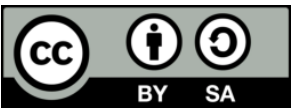

\section{Corresponding Author:}

Rania Moutchou

Research team in Electrical Energy and Control (RTEEC)

Mohammadia School of Engineers (EMI)

Mohammed V University in Rabat, Morocco

Email: rania.moutchou@um5s.net.ma

\section{INTRODUCTION}

Wind power generation has grown rapidly in recent years and has experienced a sharp increase [1], [2] which has made it a viable solution to reduce dependence on fossil fuels at rapid depletion and to adhere to environmentally friendly conditions [3]. In addition, wind is considered, one among the existing unconventional sources that can be used to meet the high demand for energy [4]. However, reducing the costs of the energy produced is crucial in order to continue to increase the penetration of wind energy [5].

Of the many dominant technologies in present-day variable speed wind power conversion (VSWECS) industry, one of the most promising and increasingly popular is the direct drive topology based on PMSG without reducer and can therefore operate at low speed [5]-[7], due to its advantages such as excellent power factor, simple control, low noise and low losses [8], [9]. In addition, the development of large-scale power electronic devices has an important role in the perfection of their controllability and reliability [10]. On the other hand, electronic power converters are mainly used as an interface between the WECS and the power grid to achieve high performance and efficiency when connected to the power grid [11]. The WECS model includes a wind turbine (WT), a PMSG, a generator side PWM rectifier to follow the maximum wind power, an intermediate DC circuit and a grid side PWM inverter to independently control the active and 
reactive power on the grid [10]. Two control strategies are applied to the control model on generator side and grid side respectively [5]. The integration of wind power generators into the grid is a critical aspect, which makes it difficult is the variation and higher intermittence of wind power generation. Thus, it is necessary to provide the appropriate synchronization techniques [12], [13].

Therefore, connecting a permanent magnet synchronous generator to a power system based on vector control (VC) theory for grid side and generator side regulation, hence the proposed control law combines the strategy of maximum power point tracking (MPPT) to increase the annual energy efficiency [14] and to maximize the power extracted with the lowest possible impact on frequency and voltage of the distribution network. The transfer of power between the distributed generation and the grid is improved by a good synchronization method. Therefore, synchronization problems between them would arise during failures. In previous works, traditional LVRT techniques have been implemented on the stability of synchronization under a weak connection [15], [16] and from the Boroïevitch team which has been working on this problem for a long time and with good progress [17]-[19] which gives a simplified model of a large signal system to achieve the stability criterion. These two working methods will cause the loss of synchronization on the converter and the power grid under severe fault and may destabilize grid synchronization. Recently, research topics such as Discrete Fourier Transform [20], Kalman filtering [21], least-squares estimation [22], artificial neural networks [23] and second order generalized integrator (SOGI) [24], have been implemented to estimate the phase and frequency of the grid. Reference [25] presents a detailed review of several algorithms and techniques that are widely used to synchronize single-phase inverters with the grid. It should be emphasized that grid synchronization is a general problem associated with grid-bound power electronic equipment [26]. To solve this problem, the interaction must be taken into consideration. Nowadays, the implementation of vector control relies on the phase monitoring of the voltage across the PMSG, which will fill a phase locked loop (PLL) [27]. It should be noted that the advantage of novel sychronisation algorithm PLL is that it avoids the problem of double frequency error with a simple structure which provides ease of parameter adjustment and robust functionality. This article discovers the network synchronization mechanism by indicating the dynamic behavior of the system as well as perfect phase tracking performance with zero phase tracking error [28], [29] or constant between the system output signal and the reference signal [30]. The results analysis displays an improvement in the system performance with higher efficacy ratio of $98,72 \%$.

The wind generation system is composed of wind turbine, a PMSG, a PWM rectifier, a PWM inverter and a phase dector. The grid side converter is controlled using the synchronous d-q reference frame approach. The PLL technique that is incorporated synchronizes the inverter and the grid. The high frequency ripple at the inverter is filtered. The filtered output of the inverter is fed into the grid through a step-up transformer as shown in Figure 1.

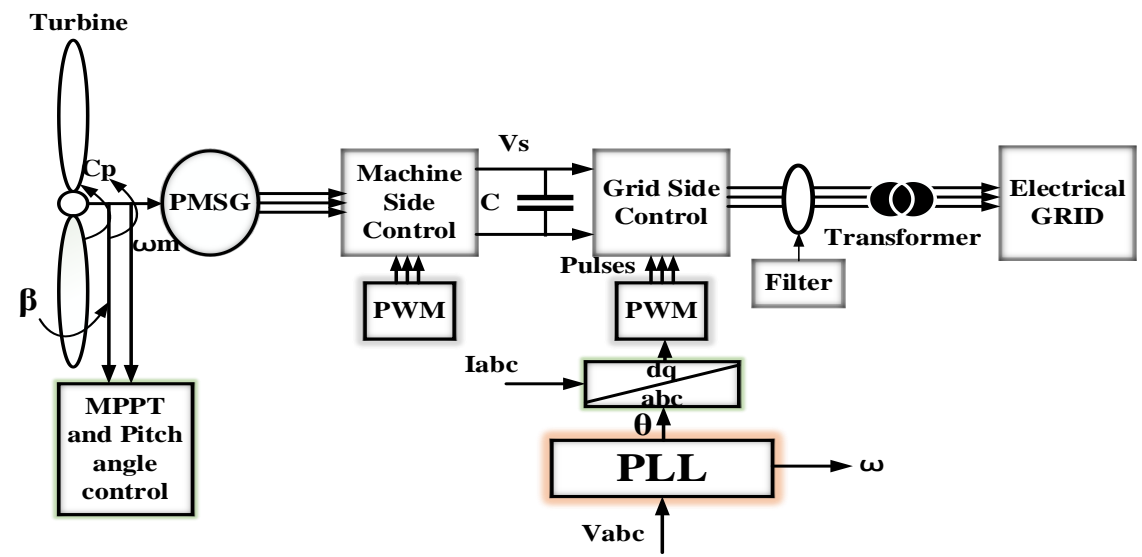

Figure 1. Schematic of WECS based on the PMSG

This paper is structured as follows. The proposed system description is describe in the second section. Furthermore, the modeling of system components is illustrated in the secondsection. Section three is dedicated to the control of machine side converters. The fourth section explains the control of grid side converters using PLL. The simulation results of the studied control topology are presented in the fifth section. At the end, a conclusion is drawn in the sixth section. 


\section{MODELING OF SYSTEM COMPONENTS}

\subsection{Wind turbine}

Taking into account the chosen wind speed $\mathrm{v}$ (Builder signal), applied to the blades of the wind turbine, the mechanical power on the turbine shaft $P_{t}$ is calculated using the [31]:

$$
P_{t}=\frac{1}{2} \cdot C_{p}(\Lambda, \beta) \cdot \rho \cdot \pi \cdot R^{2} \cdot v^{3}
$$

where $\rho$ represent respectively the density of air $(\mathrm{kg} / \mathrm{m} 3), \mathrm{R}$ is the blade radius $(\mathrm{m})$ and $\mathrm{v}$ is the wind speed $(\mathrm{m} / \mathrm{s})$ and $C_{p}(\Lambda, \beta)$ is the turbine power coefficient. Where $\lambda$ is defined by [32]:

$$
\lambda=\frac{R \cdot \Omega_{t}}{v}
$$

with $R$ the ray of pale of the wind, $C_{p}$ reactivity power coefficient and $\Omega_{t}$ the angular a velocity of the turbine $(\mathrm{rad} / \mathrm{sec})$. The wind turbine mechanical torque output $\mathrm{C}_{\mathrm{m}}$ given as [33], [34]:

$$
C_{m}=\frac{1}{2} \cdot \rho \cdot \pi \cdot R^{3} \cdot v^{2} \cdot C_{t}(\Lambda, \beta)
$$

with:

$$
C_{t}=\frac{C_{p}}{\Lambda}
$$

The power coefficient $\mathrm{Cp}$ represents the aerodynamic efficiency of the wind turbine and also depends on the characteristic of the turbine. This coefficient has a theoretical limit, called the Betz limit, equal to 0.593 and which is never reached in practice but it is between 0.4 and 0.45 [35]. In our case, the variations of $C_{p}(\lambda, \beta)$ are modeled by the following exponential approximation [36]:

$$
C_{p}=\frac{1}{2}\left(\frac{116}{\lambda_{i}}-0.4 \beta-5\right) e^{-\left(\frac{21}{\lambda_{i}}\right)}
$$

with:

$$
\frac{1}{\lambda_{i}}=\frac{1}{\lambda+0.08 \beta}-\frac{0.035}{\beta^{3}+1}
$$

And $\beta$ is the pitch angle of the blades.

Figure 2 represents the power coefficient curves as a function of $\lambda$ for different values of $\beta$. The maximum value of $C_{p}\left(C_{p \max }=0.48\right)$ is achieved for opt $\lambda=8.1$ and $\beta=0$. Besides, any change in the wind velocity or the generator speed induces change in the tip speed ratio leading to power coefficient variation. Consequently, the extracted power is affected. This power is maximized at the particular rotational speed for various wind and it is obligatory to keep the PMSG speed at an optimum value of the tip speed ratio, $\lambda_{\text {opt. }}$. Accordingly, the system can operate at the peak of the $\mathrm{P}_{\mathrm{t}}$ curve when the wind speed changes and the maximum power is extracted continuously from the wind (MPPT control) [1] is shown in Figure 3.

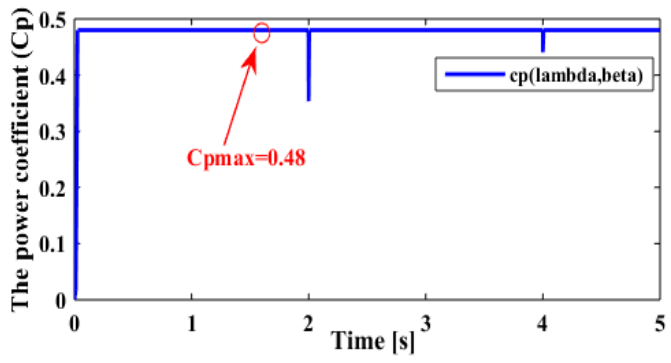

Figure 2. Power coefficient Cp with MPPT

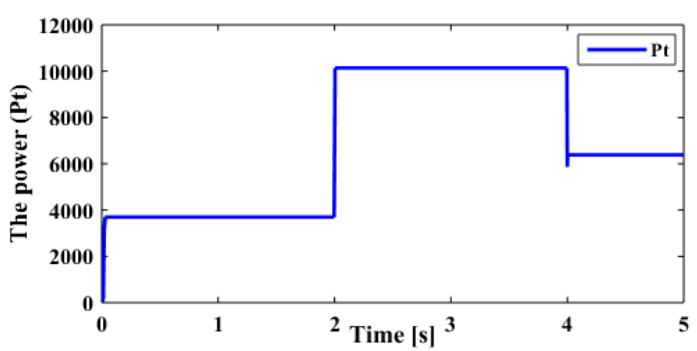

Figure 3. The Power of the wind turbine Pt with MPPT 


\subsection{PMSG system}

The PMSG drive system is composed of a generator, whose parameters are shown in Table 1, two three-phase voltage-source converters in a back-to-back topology.Taking into account the simplifying assumptions, we used the Park transformation to model the PMSG, the goal of which is to make the impedance matrix independent.

Table 1. Permanent magnet synchronous generator parameters

\begin{tabular}{ll}
\hline PMSG system & Parameters \\
\hline Power & $\mathrm{P}=10 \mathrm{KW}$ \\
Wind speed & $\mathrm{Vv}=14 \mathrm{~m} / \mathrm{s}$ \\
Nominal frequency & $\mathrm{F}=50 \mathrm{~Hz}$ \\
Number of pole pair & $\mathrm{p}=6$ \\
Stator Resistance & $\mathrm{R}_{\mathrm{s}}=0.0083 \Omega$ \\
Stator Inductance & $\mathrm{L}_{\mathrm{s}}=0.0050 \mathrm{H}$ \\
d-axis Inductance & $\mathrm{L}_{\mathrm{d}}=0.174 \mathrm{mH}$ \\
q-axis Inductance & $\mathrm{L}_{\mathrm{q}}=0.174 \mathrm{mH}$ \\
Magnetic flux & $\Phi=0.071 \mathrm{~Wb}$ \\
Moment of inertia & $\mathrm{J}=0.0089 \mathrm{kmg}^{2}$ \\
\hline
\end{tabular}

The mathematical model of a PMSG in the d-q reference framework is represented usually by (7) [37]-[39].

$$
\left\{\begin{array}{l}
v_{s d}=L_{s} \frac{d i_{s d}}{d t}+R_{s} i_{s d}-L_{s} \omega_{r} i_{s q} \\
v_{s q}=L_{s} \frac{d i_{s q}}{d t}+R_{s} i_{s q}+p \omega_{r} i_{s d}
\end{array}\right.
$$

Where $R_{s}$ is the stator resistance, $L_{s}$ the inductance of stator, $\omega_{r}$ the rotational velocity of the generator, $\mathrm{v}_{\mathrm{sd}}, \mathrm{v}_{\mathrm{sq}}, \mathrm{i}_{\mathrm{sd}}$ and $\mathrm{i}_{\mathrm{sq}}$ are stator voltage, current in the $\mathrm{d}-\mathrm{q}$ reference framework, respectively. The adaptation of equations the active and reactive stator powers of synchronous generator to the chosen system of axes and to the simplifying assumptions $\mathrm{v}_{\mathrm{sd}}=0$ and $\mathrm{v}_{\mathrm{sq}}=\mathrm{v}_{\mathrm{s}}$ considered in our case gives:

$$
\left\{\begin{array}{l}
P_{s}=v_{s} i_{s q} \\
Q_{s}=v_{s} i_{s d}
\end{array}\right.
$$

The electromagnetic torque can be described as:

$$
C_{e m}=\frac{3}{2} p\left[\left(L_{s d}-L_{s q}\right) i_{s d} i_{s q}+f i_{s q} \varnothing\right]
$$

where $\phi$ is the stator flux and $\mathrm{p}$ is the number of pole pairs of the generator. The dynamic equation of the wind turbine system is described by:

$$
J \frac{d \omega_{m}}{d t}=C_{e m}-C_{m e c}-f \omega_{m}
$$

where, $\omega_{\mathrm{m}}$ and $\mathrm{J}$ represent respectively the mechanical speed and moment of inertia, $\mathrm{f}$ is the viscous friction coefficient and $\mathrm{C}_{\mathrm{mec}}$ is the mechanical torque developed by the wind turbine.

\section{CONTROL OF MACHINE SIDE CONVERTER}

In the turbine control system, active power control and optimal wind speed monitoring are considered in the generator side rectifier control goals using the MPPT controller [40], [41]. The maximum power will be produced by the VS-WECS when the reference speed is applied to the generator speed control loop. For this reason, vector control (VC) is adopted as the control strategy in order to control the generator $\mathrm{d}$-axis stator current $\left(\mathrm{i}_{\mathrm{sd}}\right)$ and the reference current $\left(\mathrm{i}_{\mathrm{sd}}{ }^{*}\right)$ are compared and subtracted, which provides the $\mathrm{d}$ axis reference voltage signal $\left(\mathrm{v}_{\text {sd }}\right)$ through the PI controller where the d-axis cost component is set to zero to reduce copper loss, as well as for the q-axis current of the stator of the generator with its reference signal which is supplied by comparing the nominal reference rotation speed of the generator $\left(\omega_{\mathrm{m}}{ }^{*}\right)$ by its instantaneous speed $\left(\omega_{\mathrm{m}}\right)$ through the PI controller. The reference voltage of the $\mathrm{q}$ axis $\left(\mathrm{v}_{\mathrm{sq}}{ }^{\prime}\right)$ is obtained, which is shown in Figure 4. Finally, the decoupled voltages, $\mathrm{v}_{\mathrm{sd}} *$ and $\mathrm{v}_{\mathrm{sq}}{ }^{*}$, are derived as shown in (11): 


$$
\left\{\begin{array}{c}
v_{s d}^{*}=v_{s d}^{\prime}-L_{q} \omega_{e} i_{s q} \\
v_{s q}^{*}=v_{s q}^{\prime}-L_{d} \omega_{e} i_{s d}+\omega_{e} \emptyset_{f}
\end{array}\right.
$$

Finally, we use pulse width modulation PWM to produce the control signal to implement the vector control for the generator.

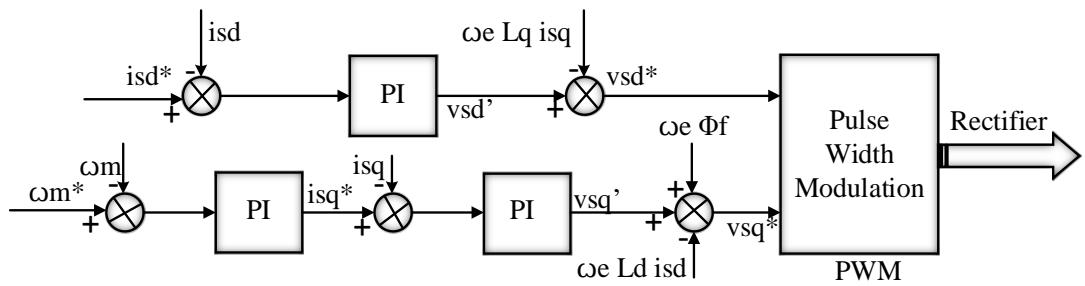

Figure 4. Control method of machine side converter

\section{CONTROL OF GRID SIDE CONVERTER USING PLL}

For the grid-side converter, the purpose of its control is to provide reliable electrical energy to consumers, to regulate the intermediate circuit voltage to a predefined reference value and to achieve a unit power factor [2], by following a specific set of parameters such as frequency and harmonic levels. In order to keep the voltage of the DC link constant, the control technique requires internal loops which independently control the $i_{d}$ and $i_{q}$ currents of the network, the active and reactive power, respectively by decoupling in a synchronous d-q reference frame. Accordingly, PI control loops are used [42]. Although the external control loop is used for the DC voltage controller. The feedback and anticipation signals are first transformed into a $\mathrm{dq}$ frame and then processed by compensators to produce the control signals. These control signals are transformed into an abc frame and sent to the network side converters [43]. Figure 5 shows the grid side converter control method.

Efficient power transfer between the grid and the source can be achieved by the efficient synchronization technique. There are many methods used so far, zero crossing method, grid voltage filtering and finally phase locked loop (PLL) method [44]. The criterion for choosing an appropriate method is based on the best response to network disturbances, for example notches, harmonics and voltage drops [45]. The PLL is used to synchronize the voltage and frequency of a given reference and output signal. A phase detector, a loop filter, and a voltage controlled oscillator (VCO) together form a basic PLL system. Therefore, PLL provides the inverter with frequency and phase angle. The goal is to synchronize the current angle of the inverter with the voltage angle of the grid in order to obtain a power factor as close as possible to 1. In Figure 6, the PLL diagram is shown.

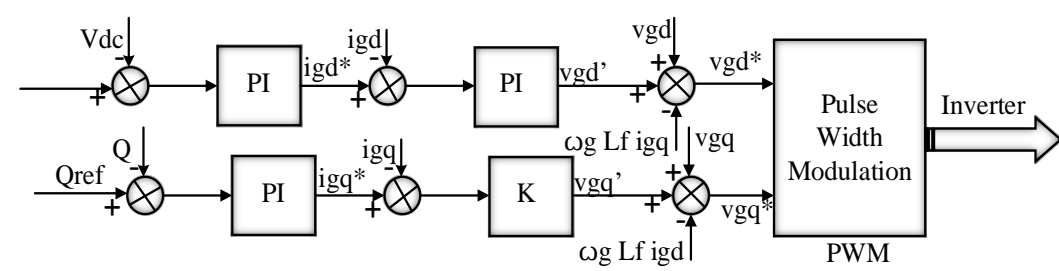

Figure 5. Control method of grid side converter

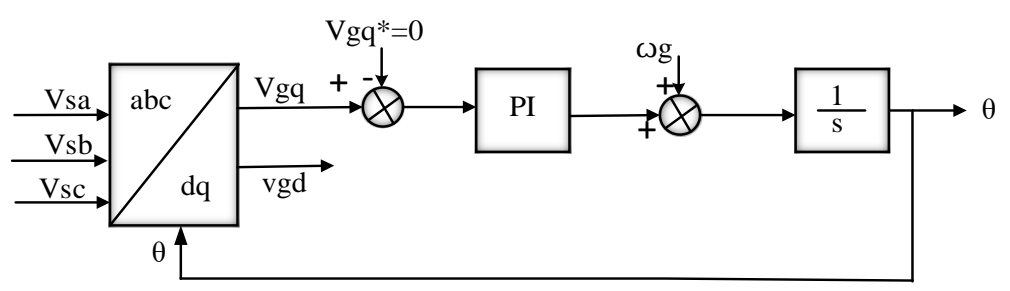

Figure 6. PLL diagram block 


\section{SIMULATION RESULTS AND DISCUSSIONS}

The models presented in this section are implemented in MATLAB / SIMULINK for its simulation, where we can see, the behavior of the system under different operating conditions. In addition, we will test the performance of the different controllers presented in the previous sections. Modeling the wind profile requires climatic and geographic data from the site concerned, as well as the period of the year concerned by the study. Therefore, several searches have been carried out. In this work, the wind profile is considered as a Builder signal, for a wind speed varies between $10 \mathrm{~m} / \mathrm{s}$ and $14 \mathrm{~m} / \mathrm{s}$ at time $2 \mathrm{~s}$ and for a change of speed at time $4 \mathrm{~s}$ of $12 \mathrm{~m} / \mathrm{s}$, as shown in Figure 7. Figure 8 shows the influence of the wind speed on the speed of rotation of the turbine controlled with the proposed strategy tracks its reference, obtained from the MPPT algorithm, successfully with a fast response, as well as the electromagnetic torque which have the same shape due to the linear relationship that exists between them. The system parameters have been listed previously in Table 1.

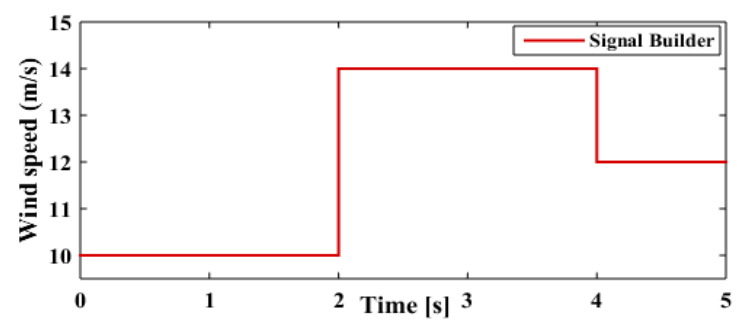

Figure 7. Wind speed $\mathrm{V}_{\mathrm{v}}(\mathrm{m} / \mathrm{s})$
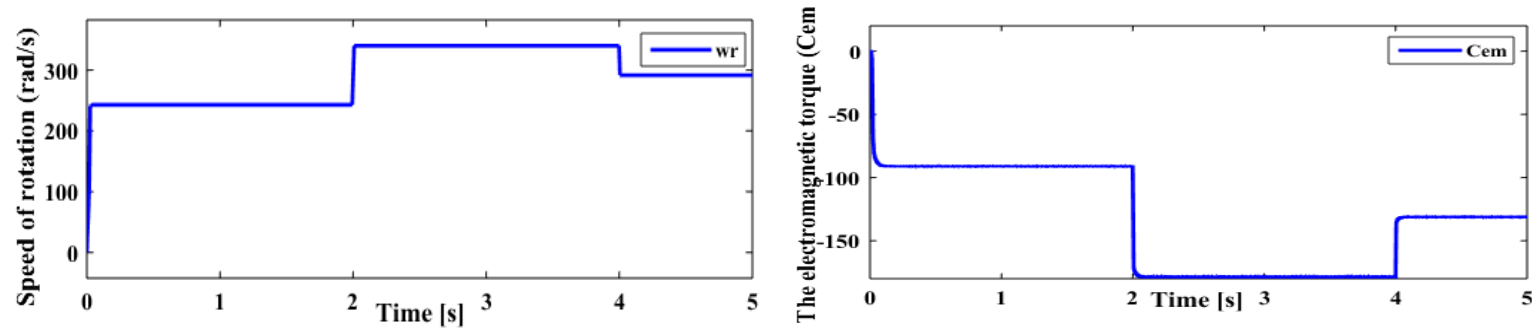

Figure 8. Speed of rotation $\omega \mathrm{r}(\mathrm{rad} / \mathrm{s})$ and the torque cem (N.m)

It is assumed that the wind power system is operating under normal conditions. As mentioned earlier, the wind power system injects its maximum active power available into the grid via machine side converter (MSC) and grid side converter (GSC) converters, to stabilize the intermediate circuit voltage when supplying local loads and check the reactive power in the event of a fault.

Figure 9 shows the intermediate circuit voltage is regulated to its desired and constant value, adjusted to settle around a continuous reference. The transient response is reduced in terms of the overshoot amplitude without updating the parameters. The DC link voltage reference and the frequency value of the electrical network are respectively $\mathrm{V}_{\mathrm{dc}-\text { ref }}=750 \mathrm{~V}$ and $50 \mathrm{~Hz}$. The output voltage of the inverter is depicted before and after PWM command in Figures 10 (a)-(b) and its responding accurately to the wind speed variations time.

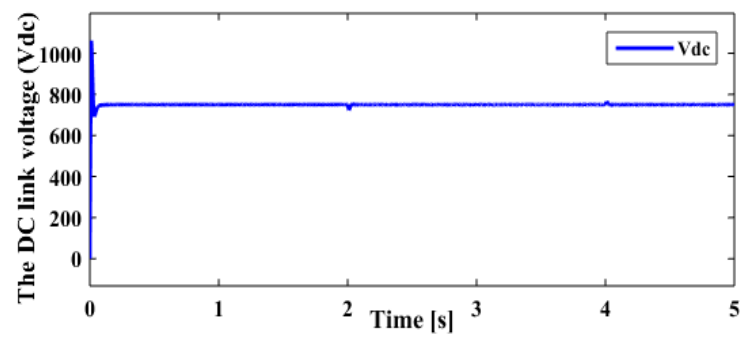

Figure 9. The DC link voltage (V) 


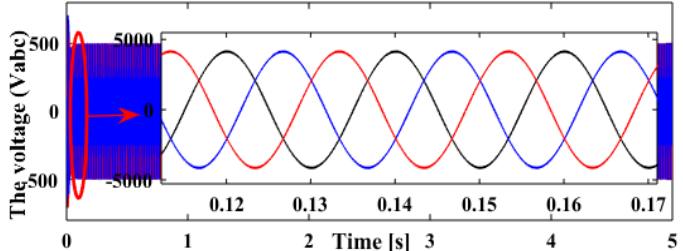

(a)

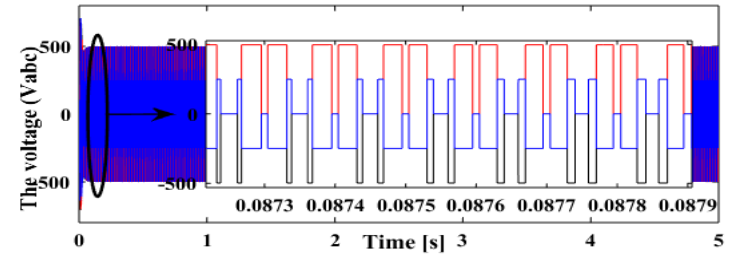

(b)

Figure 10. Inverter voltage vabc, (a) before PWM control and (b) after PWM control

The grid voltage phase locked loop (PLL) is implemented. This technique is the simplest way to track the angle and frequency of grid voltage to generate the control signal to control the power converter during the run time. In addition, the same results can be observed for the active powers $P_{g}$ and reactive $Q_{g}$ in Figure 11, respectively. During the simulation, for the grid side inverter, $\mathrm{Q}_{\text {gref }}$ is set to zero by controlling the q-axis current to zero and to ensure the unity power factor. In addition, power is generated with the most reliable impact possible on the frequency and voltage of the distribution network for fault conditions as well as for normal working conditions. As shown in the figure, the two powers are stabilized in their stationary state.

Current control techniques have been implemented in the grid-side converter model. The grid switching pulse is displayed. In Figure 12, the currents $i_{g d}$ and $i_{g q}$ injected into the network are represented with their references, this proves the efficiency of the established control systems. In addition, during simulation, the control current component $i_{\mathrm{gq}}$ is set to zero. The grid side converter performance is verfied. From figure 13, the three phase voltage $\mathrm{V}_{\mathrm{abc}}$ of the electricity network has smooth and steady signals.
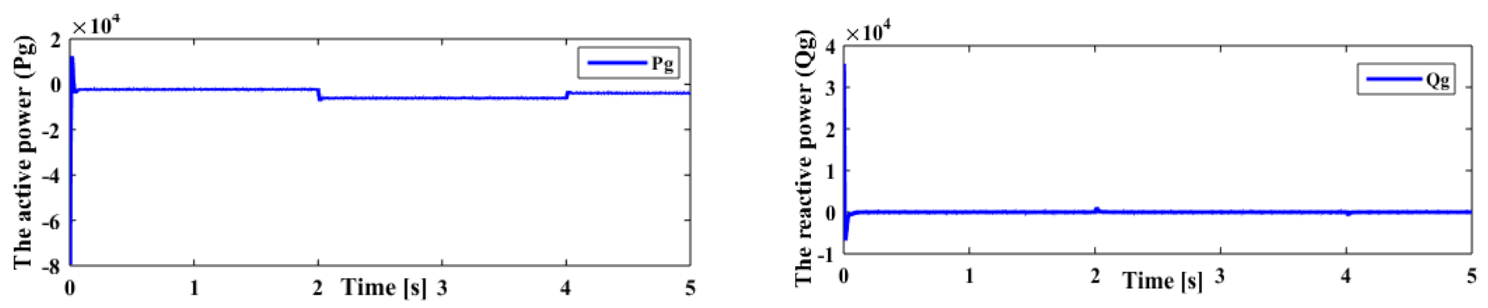

Figure 11. Active power $\mathrm{P}_{\mathrm{g}}$ and reactive power $\mathrm{Q}_{\mathrm{g}}$
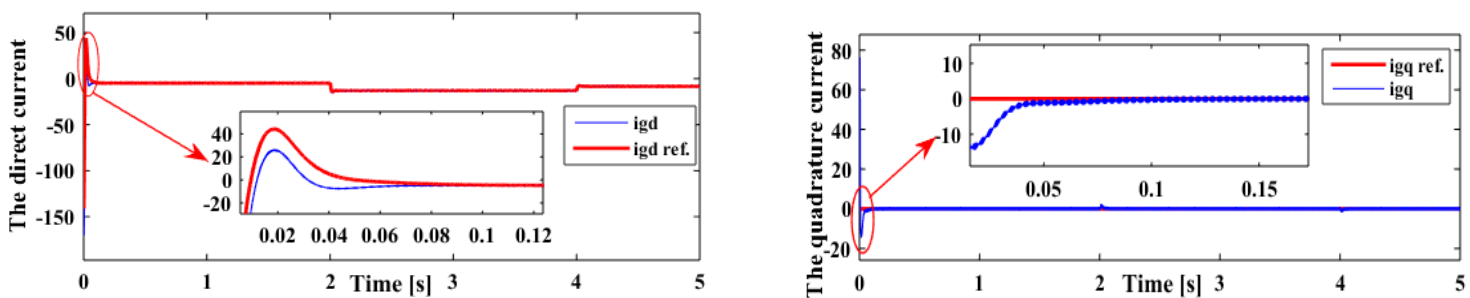

Figure 12. The currents $\mathrm{i}_{\mathrm{gd}} / \mathrm{i}_{\mathrm{gd}-\mathrm{ref}}$ and $\mathrm{i}_{\mathrm{gq}} / \mathrm{i}_{\mathrm{gq}-\mathrm{ref}}$

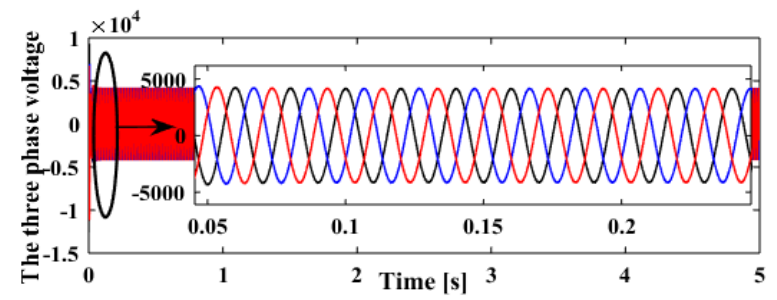

Figure 13. The voltage $\mathrm{V}_{\mathrm{abc}}$ of grid phase 
In order to enhance the quality of the work, it is necessary to check the energy satisfaction requested by the network, the superiority and the efficiency of the system to follow the maximum power during the variations of the wind. For this, we must calculate the standard deviation $\sigma$ between the power supplied by our wind power system $\mathrm{P}_{\mathrm{t}}$ of $10 \mathrm{KW}$ which was calculated using the 1 and that completed by the network $\mathrm{P}_{\mathrm{g}}$ of $0.55 \mathrm{KW}$ to supply a receiver of $10.55 \mathrm{KW}$ of power, which was established using the (12).

$$
\sigma=\frac{P_{t}-P_{g}}{P_{r e c}}
$$

It can be determined that the $\sigma$ attains 0.9 close to 1 and check that all of the power requested by the receiver is supplied by our wind turbine. Moreover, the difference between Prec and Pt of the system when the response has reached its steady state is given by (13).

$$
\varepsilon=P_{\text {rec }}-P_{t}
$$

It can be determined that the power supplemented by the network $\varepsilon$ attains 0.55 which is practically negligible, which justifies the lower energy cost of the installation. Based on the above, the ability to improve the operation and robustness of the system has been successfully demonstrated. Beyond that, the proposed PLL guaranteed synchronization, stability and while maintaining the simplicity of the system. In addition, the grid side control showed an excellent flow of active and reactive power, depending on the needs and necessities of the grid.

\section{CONCLUSION}

The study carried out allows to conclude that the control strategy of the variable speed wind energy conversion system is suitable for PMSG drives and the connected distribution network. From the responses, it has been proved that the MPPT controller is implemented to adjust the speed of the turbine as a function of the instantaneous wind speed. The proposed strategy is based on vector control (VC) theory for generator converter and PWM strategy for rectifier and inverter to keep DC link voltage constant and control active and reactive power independently, resulting in improved voltage drop. In addition, current control has better dynamic response and overall performance because of lower current distortion, higher grid power factor, and higher overall efficiency.

A built-in PLL for the grid interface is simulated and analyzed for normal grid operating conditions at constant voltage and frequency. Using PMSG with PLL grid synchronization increases the reliability of wind energy conversion systems (WECS). Finally, the simulation results show the effectiveness of the control strategies employed (no overshoot, zero steady state error and good tracking reference speed), and very good dynamic and steady state performance and working very well and very good dynamic and steady state performance and working very well with the high level of efficiency enhancement from 98,72 \%. The following progress of this effort would include but not limited to the implementation of the system under a control board to experimentally verify the system reliability and efficiency examination in the existence of grid disturbances by comparing by the results obtained.

\section{REFERENCES}

[1] Y. Xia, K. H. Ahmed and B. W. Williams, "A New Maximum Power Point Tracking Technique for Permanent Magnet Synchronous Generator Based Wind Energy Conversion System," IEEE Transactions on Power Electronics, vol. 26, no. 12, pp. 3609-3620, 2011, doi: 10.1109/TPEL.2011.2162251.

[2] S. Zhang, K. Tseng, D. M. Vilathgamuwa, T. D. Nguyen and X. Wang, "Design of a Robust Grid Interface System for PMSG-Based Wind Turbine Generators," IEEE Transactions on Industrial Electronics, vol. 58, no. 1, pp. 316 328, Jan. 2011, doi: 10.1109/TIE.2010.2044737.

[3] S. Jain, C. Ramulu, S. Padmanaban, J. O. Ojo, A. H. Ertas, "Dual MPPT algorithm for dual PV source fed open-end winding induction motor drive for pumping application," Engineering Science and Technology, an International Journal, vol. 19, no. 4, pp. 1771-1780, 2016, doi: 10.1016/j.jestch.2016.07.008.

[4] V. Yaramasu, B. Wu, P. C. Sen, S. Kouro and M. Narimani, "High-power wind energy conversion systems: Stateof-the-art and emerging technologies," Proceedings of the IEEE, vol. 103, no. 5, pp. 740-788, 2015, doi: 10.1109/JPROC.2014.2378692.

[5] R. Tanvir, and A. S. Adesara, "Control Strategy of PMSG Connected to Grid," International Journal of Scientific Development and Research IJSDR, vol. 1, no. 5, pp. 1-6, 2016.

[6] Y. Errami, M. Ouassaid, M. Maaroufi and M. Charkaoui, "Direct Torque Control and MPPT Strategy of PMSG Used for Variable Speed Wind Energy Conversion System," IEEE-International Conference On Systems and Control ICSC, June 2012. 
[7] A. Mesemanolis, C. Mademlis and I. Kioskeridis, "Maximum efficiency of a Wind Energy Conversion system with a PM Synchronous Generator," 7th Mediterranean Conference and Exhibition on Power Generation, Transmission, Distribution and Energy Conversion, 2010, pp. 1-9, doi: 10.1049/cp.2010.0868.

[8] S. Rhaili, A. Abbou, S. Marhraoui, and N. El Hichami, "Vector Control of Five-Phase Permanent Magnet Synchronous Generator Based Variable-Speed Wind Turbine," In: Proc. of International Conf. on Wireless Technologies, Embedded and Intelligent Systems, 2017, pp. 1-6, doi: 10.1109/WITS.2017.7934647.

[9] M. A. Soliman, H. M. Hasanien, H. Z. Azazi, E. E. El-Kholy and S. A. Mahmoud, "An Adaptive Fuzzy Logic Control Strategy for Performance Enhancement of a Grid-Connected PMSG-Based Wind Turbine," IEEE Transactions on Industrial Informatics, vol. 15, no. 6, pp. 3163-3173, June 2019, doi: 10.1109/TII.2018.2875922.

[10] Y. Erramia, M. Ouassaid, and M. Maaroufia, "Control of a PMSG based wind energy generation system for power maximization and grid fault conditions," Energy Procedia, vol. 42, pp. 220-229, 2013, doi: 10.1016/j.egypro.2013.11.022.

[11] Y. Errami, A. Obbadi, and S. Sahnoun, "MPPT Control for Grid Connected Wind Energy Conversion System Based Permanent Magnet Synchronous Generator (PMSG) and Five-Level Neutral Point Clamped Converter," IOP Conference Series: Materials Science and Engineering, 2020, no. 765, pp. 1-13, doi: 10.1088/1757899X/765/1/012042.

[12] M. Ramesh and T. R. Jyothsna, "A concise review on different aspects of wind energy system," 3rd International Conference on Electrical Energy Systems ICEES, 2016, pp. 222-227, doi: 10.1109/ICEES.2016.7510644.

[13] J. Z. Zhou, H. Ding, S. Fan, Y. Zhang and A. M. Gole, "Impact of Short-Circuit Ratio and Phase-Locked-Loop Parameters on the Small-Signal Behavior of a VSC-HVDC Converter," IEEE Transactions on Power Delivery, vol. 29, no. 5, pp. 2287-2296, 2014, doi: 10.1109/TPWRD.2014.2330518.

[14] C. Wei, Z. Zhang, W. Qiao and L. Qu, "An Adaptive Network-Based Reinforcement Learning Method for MPPT Control of PMSG Wind Energy Conversion Systems," IEEE Transactions on Power Electronics, vol. 31, no. 11, pp. 7837-7848, 2016, doi: 10.1109/TPEL.2016.2514370.

[15] Z. Wang, C. Shen and F. Liu, "Impact of DFIG with phase lock loop dynamics on power systems small signal stability," IEEE PES General Meeting | Conference \& Exposition, 2014, pp. 1-5, doi: 10.1109/PESGM.2014.6939310.

[16] H. Geng, J. Sun, S. Xiao and G. Yang, "Modeling and Implementation of an All Digital Phase-Locked-Loop for Grid-Voltage Phase Detection," IEEE Transactions on Industrial Informatics, vol. 9, no. 2, pp. 772-780, 2013, doi: 10.1109/TII.2012.2209666

[17] D. Dong, B. Wen, D. Boroyevich, P. Mattavelli and Y. Xue, "Analysis of Phase-Locked Loop Low-Frequency Stability in Three-Phase Grid-Connected Power Converters Considering Impedance Interactions," IEEE Transactions on Industrial Electronics, vol. 62, no. 1, pp. 310-321, 2015, doi: 10.1109/TIE.2014.2334665.

[18] D. Dong, B. Wen, P. Mattavelli, D. Boroyevich and Y. Xue, "Grid-synchronization modeling and its stability analysis for multi-paralleled three-phase inverter systems," Twenty-Eighth Annual IEEE Applied Power Electronics Conference and Exposition APEC, 2013, pp. 439-446, doi: 10.1109/APEC.2013.6520247.

[19] D. Dong, J. Li, D. Boroyevich, P. Mattavelli, I. Cvetkovic and Y. Xue, "Frequency behavior and its stability of grid-interface converter in distributed generation systems," Twenty-Seventh Annual IEEE Applied Power Electronics Conference and Exposition APEC, 2012, pp. 1887-1893, doi: 10.1109/APEC.2012.6166080.

[20] M. S. Reza, M. Ciobotaru and V. G. Agelidis, "Accurate Estimation of Single-Phase Grid Voltage Parameters Under Distorted Conditions," IEEE Transactions on Power Delivery, vol. 29, no. 3, pp. 1138-1146, 2014, doi: 10.1109/TPWRD.2014.2303482.

[21] Y. Liu, D. Yan, and H. Zheng, "Signal Frequency Estimation Based on Kalman Filtering Method," Web of Conferences, International Conference on Computer and Automation Engineering ICCAE, 2016, vol. 56, pp. 1-6.

[22] S. Golestan, E. Ebrahimzadeh, J. M. Guerrero, J. C. Vasquez and F. Blaabjerg, "An Adaptive Least-Error Squares Filter-Based Phase-Locked Loop for Synchronization and Signal Decomposition Purposes," IEEE Transactions on Industrial Electronics, vol. 64, no. 1, pp. 336-346, 2017, doi: 10.1109/TIE.2016.2599499.

[23] J. Strzeleckiand, and S. Ren, "Near-zero dead zone phase frequency detector with wide input frequency difference," Electronics Letters, vol. 51, pp. 1059-1061, 2015.

[24] P.N. Metange, K. B. Khanchandani, "Analysis and design of high performance phase frequency detector, chargepump and loop filter circuits for phase locked loop in wireless applications," Indonesian Journal of Electrical Engineering and Computer Science, vol. 4, pp.397-405, 2016, doi: 10.11591/ijeecs.v4.i2.pp397-405.

[25] N. Jaalam, N. A. Rahim, A. H. A. Bakar, C. Tan, and A. M. A. Haidar, "A comprehensive review of synchronization methods for grid-connected converters of renewable energy source," Renewable and Sustainable Energy Reviews, vol. 59, pp. 1471-1481, 2016, doi: 10.1016/j.rser.2016.01.066.

[26] H. Xin, L. Huang, L. Zhang, Z. Wang and J. Hu, "Synchronous Instability Mechanism of P-f Droop-Controlled Voltage Source Converter Caused by Current Saturation," IEEE Transactions on Power Systems, vol. 31, no. 6, pp. 5206-5207, Nov. 2016, doi: 10.1109/TPWRS.2016.2521325.

[27] W. Du, X. Chen and H. Wang, "PLL-Induced Modal Resonance of Grid-Connected PMSGs With the Power System Electromechanical Oscillation Modes," IEEE Transactions on Sustainable Energy, vol. 8, no. 4, pp. 15811591, 2017, doi: 10.1109/TSTE.2017.2695563.

[28] Ö. Göksu, R. Teodorescu, C. L. Bak, F. Iov and P. C. Kjær, "Instability of Wind Turbine Converters During Current Injection to Low Voltage Grid Faults and PLL Frequency Based Stability Solution," IEEE Transactions on Power Systems, vol. 29, no. 4, pp. 1683-1691, July 2014, doi: 10.1109/TPWRS.2013.2295261. 
[29] J. Morató, T. Knüppel and J. Østergaard, "Residue-Based Evaluation of the Use of Wind Power Plants with Full Converter Wind Turbines for Power Oscillation Damping Control," IEEE Transactions on Sustainable Energy, vol. 5, no. 1, pp. 82-89, 2014, doi: 10.1109/TSTE.2013.2273232.

[30] O. Krievs, and I. Steiks, "A PLL Scheme for Synchronization with Grid Voltage Phasor in Active Power Filter Systems," Electrical, Control and Communication Engineering, vol. 27, pp. 133-136, 2010.

[31] B. Wen, D. Dong, D. Boroyevich, R. Burgos, P. Mattavelli and Z. Shen, "Impedance-Based Analysis of GridSynchronization Stability for Three-Phase Paralleled Converters," IEEE Transactions on Power Electronics, vol. 31, no. 1, pp. 26-38, 2016, doi: 10.1109/TPEL.2015.2419712.

[32] T. Tamilarasi and M. K. Elango, "Analysis of impact on rotor angle stability of DFIG wind turbines employing STATCOM," 3rd International Conference on Advanced Computing and Communication Systems ICACCS, 2016, pp. 1-7, doi: 10.1109/ICACCS.2016.7586392.

[33] S. Tripathi, A. Tiwari, and D. Singh, "GridIntegrated Permanent Magnet Synchronous Generator Based Wind Energy Conversion Systems: A Technology Review," Renewable and Sustainable Energy Reviews, vol. 51, pp. 1288-1305, 2015, doi: 10.1016/j.rser.2015.06.060.

[34] H. Zhang, X. Wang, Y. Hou, J. Wan and J. Qi, "Operation and control strategies of wind power in West Inner Mongolia Power Grid," IEEE Power and Energy Society General Meeting, 2012, pp. 1-6, doi: 10.1109/PESGM.2012.6344833.

[35] R. Moutchou, and A. Abbou, "MPPT and Pitch Angle Control of a Permanent Magnet Synchronous Generator based Wind Emulator," International Journal of Innovative Technology and Exploring Engineering IJITEE, vol. 8, no. 7, pp. 383-390, 2018, doi: 10.5220/0009774503830390.

[36] M. A. Abdullah, A. H. M. Yatim and Chee Wei Tan, "A study of maximum power point tracking algorithms for wind energy system," IEEE Conference on Clean Energy and Technology CET, 2011, pp. 321-326, doi: 10.1109/CET.2011.6041484.

[37] Z. Liu, G. Li, Y. Ding, and C. Liu, "Transient stability studies of power system with shared transmission of wind power and thermal power," 2nd IET Renewable Power Generation Conference RPG. Pp. 1-4, 2013, doi:10.1049/cp.2013.1755

[38] F. Kamal and B. Chowdhury, "Impact of integrating DFIG and direct drive synchronous wind turbine generator on power system stability," North American Power Symposium NAPS, 2017, pp. 1-6, doi: 10.1109/NAPS.2017.8107389.

[39] J. Yan, H. Lin, Y. Feng, and Z. Q. Zhu, "Control of a grid-connected direct-drive wind energy conversion system," Renewable Energy, vol. 66, pp. 371-380, 2014, doi: 10.1016/j.renene.2013.12.037.

[40] F. Hassanzadeh, A. Hajizadeh, and F. Abbasi, "Stability analysis and optimal state feedback control of back-toback converter," Journal of Technology Innovations in Renewable Energy, vol. 2, no. 2, pp. 139-144, 2013.

[41] S. Rhaili, A. Abbou, S. Marhraoui, N. El Hichami and A. V. Hemeyine, "Robustness investigation of Vector Control of Five-phase PMSG based Variable-Speed Wind Turbine under faulty condition," Renewable Energies, Power Systems \& Green Inclusive Economy REPS-GIE, 2018, pp. 1-6, doi: 10.1109/REPSGIE.2018.8488809.

[42] M. Bouderbala, B. Bossoufi, A. Lagrioui, M. Taoussi, H. A. Aroussi, and Y. Ihedrane, "Direct and indirect vector control of a doubly fed induction generator based in a wind energy conversion system," International Journal of Electrical and Computer Engineering IJECE, vol. 9, no. 3, pp. 1531-1540, 2019, doi: 10.11591/ijece.v9i3.pp15311540.

[43] O. A. Mejía, R. T. Olvera and J. M. S. Solorio, "Wind energy conversion system using PMSG controlled by Bspline network," IEEE PES T\&D Conference and Exposition, 2014, pp. 1-5, doi: 10.1109/TDC.2014.6863435.

[44] H. Athari, M. Niroomand, and M. Ataei, "Review and classification of control systems in grid-tied inverters", Renewable and Sustainable Energy Reviews, vol. 72, pp. 1167-1176, 2017, doi: 10.1016/j.rser.2016.10.030.

[45] S. Heier, "Grid Integration of Wind Energy: Onshore and Offshore Conversion Systems," 3rd Edition 2014. 